\title{
Teacher's professional image: reimagining the future
}

\author{
N.B. Samoylenko ${ }^{*}$, L.N. Zharko ${ }^{2}$, and A.A. Georgiadi ${ }^{3}$ \\ ${ }^{1}$ Sevastopol State University, Sevastopol, Russia \\ ${ }^{2}$ University of Economics and Managment, Simferopol, Russia \\ ${ }^{3}$ Sevastopol State University, Sevastopol, Russia
}

\begin{abstract}
In this research, the authors aim to determine the teachers' professional image in the present-day context. The issues of teachers' new role, new image and professional conditions are analyzed with regard to the reforms and commercialization of higher education as the most common trends. The paper examines the data of the survey which was conducted on the basis of written questionnaire designed to investigate the university teachers' readiness to work in the new conditions, their readiness to innovation, the factors constraining innovation in the sphere of higher education in the context of its commercialization. The research carries value to education policymakers and university authorities. They can use these findings to reflect on regulations that would ensure favorable academic environment and increase the brand image of their staff.
\end{abstract}

\section{A problem statement}

According the Professional standard the main requirement for high-quality professional education at the present stage is comprehension of who professionals are, what their way of life is like, what purpose in the world they have, what role in various spheres of life they play, as well as the social and political demands for their education, and their expectations from education, society, and professional sphere. Such characteristics of a successful professional as readiness for change, mobility, ability to non-standard professional actions, responsibility and independence in decision making are fully applied to the teacher, according to the professional standard, which increases responsibility for the results of their work [1].

The relevance of the problem of teachers' professional growth is, on the one hand, due to aspirations of society, state, and education system to ensure a high level of education against the background of the constant growth of teachers' professionalism. Zharko L. claims that on the other hand, it stems from the increasing complexity, scale of "challenges to humanity" and ideas about the value foundations of human life. It can be stated that recently the teaching profession has become widespread and it is, to a greater extent, "female" in nature against the background of the lack of scientific criteria for selecting

\footnotetext{
*Corresponding author: ipcs-profped@yandex.ru
} 
applicants [2]. But the teacher, like no other, fulfills the state order for training, personality formation, education of the younger generation that is the basis of the socio-cultural and moral life in future.

In this regard, the necessity for a teacher of a new formation, who will be motivated to self-development, interested in fostering and using their creative potential, apply modern technologies and forms of education has appeared. The formation of the teacher's image in the context of the education system transformation is becoming increasingly important. It is the fact that determines the relevance of the issue under study.

The future of education - discussed at the international and national levels, aspired to in strategic educational documents and waited for decades - has come. Annual celebrations of the World Teachers' Day (traditionally commemorating 1966 ILO/UNESCO Recommendations concerning the Status of Teachers) this year are proclaimed to be a perfect opportunity to celebrate and reflect on the hard work and effort that everyone involved in education has done to adapt and continue teaching in new and difficult circumstances [3https://www.teachingenglish.org.uk/article/world-teachers-day-webconference-2020]. Boris Radanovic observed that obviously, we can no longer say 'the future' of digital technologies because we are now at the centre of technological assistance to our way of life with teaching, socialising, educating, working, and other patterns changed in recent months [4]. The issues of professional self-development, online safety, current trends and challenges of the digital world as well as teachers' responsibility in the new environment as it was mentioned in World Teachers' Day 2020, have now become everyday reality for all representatives of the teaching profession globally. In COVID-19 crisis "without much warning and with little time to prepare, teachers have had to modify or condense the curriculum and adapt lesson plans to carry on with instruction, whether via the internet, mobile phone, television, or radio broadcast" [5].

In regard to the world's sustainable development ensuring quality teacher education is viewed as a key to building resilient education systems. Sustainable development goals 4 stress that in view of possible future crises it is necessary to invest in quality pre-service teacher education by better preparing teachers for the classroom including innovation and problem solving to manage complex unforeseen situations; as well as invest in continuing professional development (CPD) and in-service education and training (INSET) to upskill under- or unqualified teachers so that all teachers have the knowledge and skills necessary to ensure no one is left behind [6].

This is a unique situation for demonstrating teacher leadership, creativity, and innovation which are highly valuable in the modern world. Still it must be viewed against the background of economic realia that in the sphere of education appear as its commercialization.

Swapnali Borgohain claims that commercialization of education has been fairly a recent trend impacting the traditional concepts of education in the society. Generally, commercialization is a process of introducing a new product or service into the general market. Aimed at healthy competition for the benefit of the buyer (the student), commercialization of education is a trend of decreasing emphasis on the humanities and focusing attention on the students' demands [7]. Seen as driven by thought in the former days, education has now to undergo changes in the student teacher relationship, the educational process itself as well as attitude towards gaining knowledge.

The complexity of the situation provokes thought and leaves enough space for debating the professional image of the modern teacher. 


\subsection{The objective of the work}

Although the new remote mode of teaching in recent months has considerably increased the burden of workload in the sphere of higher education, there is little evidence as to how academics experience the change and how the change influences there attitude to innovation and reforms in the Russian system of higher education. The paper examines the data of the survey which was conducted on the basis of written questionnaire designed to investigate the university teachers' readiness to work in the new conditions, their readiness to innovation, the factors constraining innovation in the sphere of higher education in the context of its commercialization. The findings show that most academicians are motivated to take part in innovation of higher education, although more than a half of them do not support the ongoing reform and view commercialization of education as a negative phenomenon. The main constraint on the way to applying innovative methods in higher education is heavy workload. The research carries value to education policymakers and university authorities. They can use these findings to reflect on regulations that would ensure favorable academic environment and increase the brand image of their staff.

\section{Materials and the results of the research}

The purpose of the study was to discover what the teachers' professional image is like in the present-day context. The objectives included 1) description of the main features of the teaching profession at present (after the outburst of COVID-19 pandemic); 2) clarification of the definition of the teachers' professional image; 3) considering the components of the teachers' professional image; 4) presenting the survey results on the issues of teachers' motivational readiness to work in the new conditions, their readiness to innovation, the factors constraining innovation in the sphere of higher education in the context of its commercialization.

At the World Teachers' Day Web Conference 2020 the situation with a hybrid-learning model will be discussed. With the beginning of the autumn term at universities, it has become clear that one of the products of half a year teaching in new conditions is a hybridlearning model which aims to combine face-to-face and remote tuition into a coherent whole [3]. However, it is not clear yet what this model implies both for the teacher and the student. As a facilitator for the students the teacher must be able to draw the pedagogical advantage of the context by getting better prepared to face the pitfalls wisely and efficiently. The issue of teachers' wellbeing becomes critical for good practice, so it needs the development of new strategies that at policy and institutional levels would guarantee the necessary conditions for the realization of the potential of online instruction.

The issues of teachers' new role, new image and professional conditions should be viewed with regard to the reforms and commercialization of higher education as the most common trends.

The merits of commercialization of education from the viewpoint of western scholars include 1) employment opportunity both for teachers and students which reduces the unemployment problem of the country; 2) economic development of the country through increase in the rate of literacy, Gross Domestic Product, Gross National Income; 3) commercialization of education helps to face such global challenges as modernization, industrialization, privatization, globalization, information and communication technology etc.; 4) personality development of students the development of commercialization skill, soft skill, skills of health maintaining; 5) quality of education in terms of the quality of the learner, quality of the learning environment, quality content, quality process and quality outcomes; 6) increase in the number of private institutions; 7) social development through provision of education in accordance with the needs of the society; 8) fulfillment of 
parents' expectation investing in education; 9) development of professional efficiency of teachers through provision of training; 10) professional and vocational development of learners [7].

Swapnali Borgohain points out that the demerits of commercialization of education reveal the controversial character of the phenomenon as education is found 1) focusing on marks; 2) unable to maintain the principle of quality in search of profit; 3) expensive; 4) forming materialistic outlook; 5) overburdening teachers without paying them sufficient amount of money; 6) mechanical in its process as it does not follow psychological principles; 7) unfavorable for teacher development [7].

The United Nations Sustainable Development Group, having analysed the data on the impact of COVID-19 pandemic on education, defines the current situation as the deepest global recession in living memory which will have lasting effects on economies and public finances and eventually education. National authorities and the international community are called on to protect education financing through the following avenues: strengthen domestic revenue mobilization, preserve the share of expenditure for education as a top priority and address inefficiencies in education spending; strengthen international coordination to address the debt crisis; and protect official development assistance (ODA) for education $[8]$.

Still universities are also viewed as centres of 'spiritual life of the human being'. In this respect Joan Pedro-Caranana (2020) relying on historical facts insists that 'universities require protection and investment by the political powers so that they can pursue their mission to contribute to the humanization of societies'. This requires the effective public health measures, and a guarantee of the conditions needed for cooperation and dialogue, mobility and autonomy [9].

By our opinion, in Russia, traditionally university has been a special type of social institution different from political and market organizations. The difference lies in independence from external influences and collegiality as a way of organizing internal activities. With the change in traditional academic values and the onset of structural changes in the organization of academic activities, universities began to lose their exclusive status. In the context of the formation of a knowledge society, the boundaries between academic institutions and other types of organizations are blurring.

Anokhina Y.A. considers that like in many other countries commercialization of education in Russia used to be a lever for generating additional income. These days, however, the triple helix concept of entrepreneurial university is being implemented. The model of the triple helix, describing the process of innovative development as a balanced relationship between the university, the state and business, relies on the leading role of the university in these relations. This implies the change of the university mission. The leading role of university has the key status and expresses itself in the second academic revolution the emergence of a new function of entrepreneurship, incubation, and the creation of their own companies [10]. The new model implementation is aimed at the development of the domestic market of science-intensive products and resource provision of higher education, as well as at making a significant contribution to the modernization of the entire domestic economy. The development of universities entrepreneurial activity is necessary not only for the adaptation of science to the market, but also to give the domestic market a civilized look. The main potential consequences of the commercialization of higher education are expected to happen 1) in the sphere of culture: the emergence of direct competition in groups of teachers, scientists, managers and students; the transition from collective to individualized consciousness; 2) in the political sphere: strengthening the autonomy of universities; decrease in the number of universities; 3) in the economic sphere: decrease in government expenses on higher education; an increase in the costs of the innovative 
business environment for training specialists with higher education; growth of credit debt on educational loans; 4) in the social sphere: decrease in the total number of students [10].

Digitalisation of economy proclaimed in Russian Federation implies transformation of classical university into a digital one that could ensure the formation of the key competences. According to Kuzina G. (2019), The educational process must be constructed of the educational modules and courses from leading Russian and foreign universities. Meanwhile the digital university concept implies the use of a wide range of new technology for evaluation of students' competences and personal traits. The realization of the educational programme will be based on the cooperation of the digital university with a range of other educational institutions, digital platforms and companies [11].

Carrying out research in the field of digitalization, Kagermann \& Winter (2020) stress that nowadays, in times of radical transformation, companies need entirely new competences, for example in data connection and analysis through AI and machine learning. They are increasingly looking to gather these in science and applied research. This gives the design and optimisation of knowledge, technology, and information transfer renewed urgency. However, the established forms of knowledge transfer between science and economy are also facing major challenges - be it the transfer through humans, cooperations, or spinoff companies. Companies and science must be open to new cooperation partners and, in doing so, overcome cultural barriers. A last clear and firmly anchored objective should revolve around transfer in the science system, besides research and teaching. We need a closer dialogue between science and economy to shape complex future tasks [12].

Digitalisation of economy is seen as the key issue both at the national and international levels. In terms of education teachers are provided with theoretical and practical advice on how to change their traditional mode of work and plunge into the world of technology. The tasks of teachers' rearranging their vision of profession and activity embrace a wide scope starting from the provision of basic tips for beginners [13] and recommendations on the use of open educational resources [14] to coping with psychological problems of remote teaching like keeping students' attention [15], finding ways to improve students' perception for better education quality $[16,17]$, and using behavioral science to solve problems of online education $[18,19]$.

One of the successful conditions for organizing effective e-learning is the formed media and information literacy of the teacher in the development of digital technologies; the ability to apply modern distance learning technologies and e-learning in the educational process [20].

Professional competence is one of the main components of teachers' professional maturity, which, along with the focus of the personality on creative achievements and teaching skills such as the ability to solve standard and new problems of practice becomes the main criterion for professional development. Based on theoretical research on professional development, the main characteristics that act the teacher's readiness for professional creative activity as the basic components of professional maturity include 1) personal and humane orientation as well as emotional and moral readiness; 2) theoretical and cognitive readiness determined by the level of proficiency in special scientific, philosophical, psychological and pedagogical knowledge, the system of psychological and pedagogical knowledge, knowledge of the subject and methods of teaching it; 3) constructive design readiness associated with the possession of skills and abilities of professional activity, methods of mental and practical activity; 4) general erudition, general cultural readiness; 5) professional and personal qualities: creativity, reflection, professional and communicative tolerance, empathy, pedagogical flexibility; 6) the ability to correlate one's activities with the world pedagogical culture, pedagogical abilities and professional pedagogical culture; 7) high motivation for achievement, creativity, the need for creative 
activity and self-realization, striving for success. Thus, the teacher's professional maturity becomes the core and integrator of the criteria and indicators of professional development presented below in their close relationship.

As a result, the external factors influencing teacher's professional competence include laws and legal acts presenting demands to professionals. In this regard the documents depicting the situation in Russian education are professional standards. The professional standard of a pedagogue must 1) correspond to the structure of professional activity of the teacher; 2) not turn into a tool for strict regulation of the teacher's activities; 3 ) encourage the teacher to search for non-standard solutions; 4) comply with international standards and regulations; 5) correlate with the requirements of relevant ministries and departments that determine the calculation of work experience, pension accrual, etc.

The professional standard of a teacher is a framework document that defines the main qualification requirements. The national framework of the standard can be supplemented with regional requirements taking into account the socio-cultural, demographic and other features of the territory (megacities, areas with a predominance of rural population, monoethnic and multi-ethnic regions impose their own specifics on the teacher's work).

The teacher must be always open to new things, ready to acquire knowledge with the students, must not be afraid to seem incompetent. A good teacher admits the existence of an opinion that does not coincide with his own. A modern and competent teacher has technical training tools that correspond to the digital age.

The higher education system should move from an authoritarian format to the one based on humanistic partnership. The mutual role transformation of students and teachers becomes necessary. Meanwhile, the image acts as a means of readiness and the ability of the social actor to the expected (sometimes forced) transformation. This determines the relevance of sociological research on the image of a university teacher in the process of educational interaction which allows to identify the degree of compliance of the teachers' behavior goals with the demands of the society and social interaction partners (expectations of the society and student as partners) during the transformation of society. Image is the top of the iceberg that the teacher deliberately demonstrates to students. This openness allows sociologists to study the development of educational interaction, and in the period of its transformation, highlight its imbalances and contradictions.

In the context of modernization of the Russian education system personal and professional development of a teacher is becoming particularly relevant which is determined not only by educational policy requirements, but also by the requirements of rapid social and technological processes, as well as parents' and students' needs.

The image of a modern university academician is a set of criteria and indicators for the quality of the professional activity, which is inextricably linked to the effectiveness of the professional development process.

Zharko L. (2018) in her study relies on the model of a teacher consisting of the three blocks of characteristics denoted 1) teacher as a personality, 2) teacher as a specialist, 3) teacher as a professional [21] (table 1).

Thus, only the complex of the considered components will make it possible to talk about the ideal teacher.

The main factors of the teacher's professional development, in our opinion, are systemic management of the activities, organization of innovative activity as a new business and interpersonal structure of the teacher's professional activity, motivational management, monitoring as a system for analyzing and evaluating the activities of a teacher, his continuous education. The latter is considered as the essence of professional and personal development, as the internal process, as the process of self-development and selfaffirmation of the teacher's personality. 
Table 1. Structural characteristics of teacher at modern stage.

\begin{tabular}{|l|l|l|}
\hline № & Components & \multicolumn{1}{c|}{ Description of the requirements } \\
\hline 1 & $\begin{array}{l}\text { Teacher as a } \\
\text { personality }\end{array}$ & $\begin{array}{l}\text { - organizational skills, activity, eloquence, } \\
\text { - fairness, tact, benevolence, correctness in relation to students; } \\
\text { - open-mindedness, general erudition; } \\
\text { - sociability; } \\
\text { - discipline, responsibility; } \\
\text { - tolerance; } \\
\text { - sense of humor; } \\
\text { - personal charm; } \\
\text { - love for their profession; } \\
\text { - emotional resistance to stress. }\end{array}$ \\
\hline 2 & $\begin{array}{l}\text { Teacher as a } \\
\text { specialist }\end{array}$ & $\begin{array}{l}\text { - Fundamental academic education; } \\
\text { - in-depth knowledge of the subject taught, related disciplines. }\end{array}$ \\
\hline professional a & $\begin{array}{l}\text { - Skills in the sphere of modern teaching technologies, pedagogical } \\
\text { concepts, methods of motivating educational activities, research methods, } \\
\text { etc.; } \\
\text { - the ability to evaluate and implement innovative products in the } \\
\text { educational process. }\end{array}$ \\
\hline
\end{tabular}

To investigate the university teachers' readiness to work in the new conditions we conducted a survey among a sample of 40 academics from the Sevastopol State University, the Crimean Federal University named after V.I. Vernadsky, and Crimean Engineering and Pedagogical University named after Fevzi Yakubov. The questionnaire was presented online and in paper. The gender profile was presented by $34 \%$ of women and $6 \%$ of men, which confirms our statement about feminization of the teaching profession. The respondents of the survey fell into three categories by age: $25-35$-year-old teachers made up $30 \%, 36-50$-year-olds $-37,5 \%$, and teachers aged over $50-37,5 \%$. In other words, we can talk about the relative equality of "young" teachers, middle-aged teachers, and age-related teachers.

The ongoing reform in the field of education is not supported by $57.5 \%$ of respondents, $35 \%$ of them are partially satisfied with the reform process, and only $7.5 \%$ of respondents are satisfied with the current changes.

Against the background of globalization, commercialization of the educational system is viewed as a negative phenomenon by $52.5 \%$ of respondents, $15 \%$ of respondents have a positive attitude to commercialization, and $32.5 \%$ have not decided yet how to treat it. It is quite natural that $60 \%$ of respondents do not consider education to be a service, while and $40 \%$ of respondents agree that it is.

Readiness for innovation was found to be at the average level in $98.08 \%$ teachers, while $1.92 \%$ showed low level of this quality, and there were no respondents' confirmation of high level.

As for motivational readiness to master innovations, teachers indicated the following reasons as important (ranging from 1 to 4):

1. awareness of the insufficiency of the results achieved and the desire to improve them, the need for research;

2. the desire to create an effective atmosphere in the group, the need for novelty, overcoming routine, the need for contacts with interesting, creative people, the desire to test in practice the gained knowledge about innovations, a sense of their own readiness to participate in innovative processes, self-confidence;

3. the need for self-expression, self-improvement, the need to achieve high results, material reasons;

4. the desire to be noticed, the need for leadership, risk. 
Among the reasons that hinder the implementation of innovative activities, teachers indicated:

1. heavy workload at work;

2. lack of financial incentives;

3. lack of awareness;

4. the belief in the effectiveness of training "in the old way";

5. poor health, the effects of "burnout".

The survey led to the following conclusions:

The survey made it possible to draw the following conclusions:

Among professional qualities, an innovative type of thinking is of particular importance, which allows not only to see, but also to predict the likely prospects and results of professional pedagogical activity.

Even though education is subject to commercialization processes [22], most teachers are not used to the idea that they provide students with an educational service.

It is clear from the results of this study that the problem of the image of a teacher in higher education has not received independent holistic coverage yet. The professional and individual images of a teacher are inseparable and always remain to be the focus of public attention, since there exist stable requirements to communicative attitudes, which may or may not meet the expectations and the demands of society. The requirements to the professional image are the same in all groups of respondents. They include knowledge of the subject, professionalism, availability of explanation, objectivity, ability to plan work, exactingness and self-organization. Differences are revealed in relation to the individual and personal qualities of the teacher. For teachers and experts, communication and communication skills are important, while for students psychological aspects of interaction (the manner of communication, perception and understanding) are essential. At the same time, the personality of the teacher presented in the image turned out to be more important for students than for teachers themselves. Every other teacher creating his own image relies on psychological motivation focused on self-awareness, which makes them "closed" in the process of interaction.

\section{Conclusions}

The present-day situation in education is characterized by the process of feminization at all levels. The age gap connected with the problems which appeared during the years of reforms and crisis in the Russian Federation resulting in aging of academic staff has revealed itself. The quality of scientific and pedagogical personnel changed: some talented teachers emigrated to economically more developed countries, went to work in commercial, political structures or government structures, and they were substituted by less qualified specialists, unclaimed in other spheres, while or practice oriented specialists came to education from bankrupt enterprises and disbanded institutions.

The reality of this situation, in our opinion, further exacerbates the problem of building effective educational interaction. Its essence lies in the discrepancy between the status and role requirements of modern Russian society and the qualities of real performers of the roles of university teachers at the present stage of the Russian education system development.

From the above discussion it is clear that commercialization has both the positive and negative impact on education. Without privatization commercialization can't take place. Education is to bring out the potential in a learner by providing the leaner the most congenial physical and social environment to help him realize his fullest potential. Education on the other hand is an industry and its commercialization is here to stay. At the end we can say that for these people education has today become on option to make money 
than providing quality education to students. But due to the presence of this tendency it is helpful for the government for reducing their work burden and for the students to cope up with the modern society.

In the end we can decide that the development of any nation depends mainly on the standards of its educational system. Education is the most powerful and effective instrument for including radical changes in the behavior of students. It is a powerful instrument of nation's social economic and cultural development. There reforms envisage the withdrawal of state from its social obligations once for all. Thus, each country should decide what can be constructively introduced in their socio-economic and educational system.

\section{References}

1. Order of the Ministry of Labor and Social Protection of the Russian Federation of September 8, 2015, On the approval of the professional standard Teacher of vocational training, vocational education and additional vocational education, (in Russ.), access mode: http://base.garant.ru/71202838/ (2015)

2. L.N. Zharko, The role of the teacher in the formation of a competitive specialist in the higher education system, Professionalism and citizenship - the most important priorities of Russian education in the XXI century: Proceedings of pedagogical readings dedicated to the $27^{\text {th }}$ anniversary of Johann Heinrich Pestalozzi on December 3, 128-132 (in rus.) access mode: http://www.vgpgk.vrn.ru/files/2016 12 20/СБОРНИК\%20ПЧ2016\%20ЧАСТЬ $\% 203$ 16.12.pdf $(2016)$

3. World Teachers' Day Web Conference 2020, access mode: https://www.teachingenglish.org.uk/article/world-teachers-day-web-conference-2020 (2020)

4. B. Radanovic, Staying safe online in the new school year, access mode: https://www.teachingenglish.org.uk/article/world-teachers-day-web-conference-2020 (2020)

5. UNESCO World teachers' day 2020, access mode: https://en.unesco.org/commemorations/worldteachersday (2020)

6. SDG-Education 2030 Steering Committee, Ensuring quality teacher education: a key to building resilient education systems, access mode: https://sdg4education2030.org/node/405

7. S. Borgohain, International Research Journal of Interdisciplinary \& Multidisciplinary Studies, I (XII), 71-76, access mode: http://oaji.net/articles/2016/17071457180816.pdf

8. United Nations Policy Brief: Education during COVID-19 and beyond, access mode: https://unsdg.un.org/sites/default/files/2020-08/sg_policy_brief_covid-

19_and_education_august_2020.pdf (2020)

9. J. Pedro-Caranana, Post-pandemic university or post-university, access mode: https://www.researchgate.net/publication/344165647_Post-

pandemic_university_or_post-university

10. Yu.A. Anokhina, Commercialization of higher education: socio-cultural and economic aspects (St. Petersburg Educational Bulletin 9-10, 14-20), (2017), (in rus.), access mode: https://cyberleninka.ru/article/n/problemy-kommertsializatsii-vysshegoobrazovaniya-sotsiokulturnye-i-ekonomicheskie-aspekty 
11. G. Kuzina, The Concept of a Digital Transformation of a Traditional University to a Digital University, access mode: https://www.researchgate.net/publication/343983858_The_concept_of_a_digital_trans formation_of_a_traditional_university_to_a_digital_university (2020)

12. Henning Kagermann, Johannes Winter, The Second Wave of Digitalisation, access mode:

https://www.researchgate.net/publication/344106566_The_Second_Wave_of_Digitali sation/link/5f526c2192851c250b8ff39f/download (2020)

13. Teaching online for the first time: 7 tips for those about to sail into uncharted waters, access mode: https://differentefl.blogspot.com/2020/03/teaching-online-for-first-time7-tips.html? $\mathrm{m}=1$

14. UNESCO Recommendation on Open Educational Resources, access mode: https://unesdoc.unesco.org/ark:/48223/pf0000370936

15. G. Stanley, Remote teaching - how to keep learners' attention, access mode: https://www.britishcouncil.org/voices-magazine/remote-teaching-how-keep-learnersattention

16. H.S. Akareem, S.S. Hossain, Determinants of education quality: what makes students' perception different?, Open Review of Educational Research, 3 (1), 52-67, access mode: http://dx.doi.org/10.1080/23265507.2016.1155167 (2016)

17. L. Fesler, Opening the Black Box of College Counseling using Text-as-Data Methods, access

mode: https://www.researchgate.net/publication/340413916_Opening_the_Black_Box_of_C ollege_Counseling

18. R.F. Kizilcec, J. Reich, M. Yeomans, C. Dann, E. Brunskill, G. Lopez, S. Turkay, J. Williams, T. Tingley, Scaling Up Behavioral Science Interventions in Online Education, Proceedings of the National Academy of Sciences, 117, 26, access mode: https://www.pnas.org/content/117/26/14900

19. A. Rafferty, Recognizing student strategies and misunderstanding using inverse planning, access mode: https://iriss.stanford.edu/css/conferences/conferenceeducational-data-science/agenda

20. N.B. Samoylenko, Language portfolio: students' autonomous learning and language learning achievements, Scientific Letters of Academic Society of Michal Baludansky, 3 (6), 124-130 (Slovakia, 2018), access mode: https://www.researchgate.net/publication/330968133_PREPARING_STUDENTS TO MEET THE_DEMAND_FOR 21_CENTURY_SKILLS_OPPORTUNITIES CHALLENGES EXPECTATIONS

21. L.N. Zharko, The Personality of the Teacher as a Factor of Successful Functioning of System of Additional Professional Education, Young science: collection of scientific works scientific-practical conference for students and young scientists, "ARIAL", access mode: http://www.ma.cfuv.ru/res/240229/2018\%20СБОРНИК.pdf (Simferopol, 2018)

22. Russian Federation Laws, Federal Law On Education in the Russian Federation of December 29, 2012, No. 273-FZ, (in rus.) access mode: http://www.consultant.ru/document/cons_doc_LAW_140174/ (Moscow, 2015) 